\title{
Correction to: Contraception and abortion knowledge, attitudes and practices among adolescents from low and middle-income countries: a systematic review
}

\author{
Margarate Nzala Munakampe $e^{1,4^{*}}$, Joseph Mumba Zulu² and Charles Michelo 3,4
}

\section{Correction to: BMC Health Serv Res https://doi.org/10.1186/s12913-018-3722-5}

In the original publication of this article [1], there are several errors. The original sentences and corrections are listed below:

1. Some parents acknowledged that teaching sexual and reproductive health to adolescents bordered on incest (7) and they were in favour of traditional teachings during initiation ceremonies or before marriage (19)

Change "bordered on incest" to "were uncomfortable", and delete citation 7 .

2. Apart from parents, other family members including aunties, uncles, brothers, sisters, and cousins were available, but not a preferred source of information. However, they were influencers of abortion decisions $(7,8,11,16,17,18,19$,).

Delete citation 7

3. Emergency contraception was not covered in school sexuality education (7)

Change "was not covered" to "scarcely covered".
4. Morally, adolescents viewed abortion as a sin and that it was wrong $(3,6,7)$

Change "adolescents" to "some adolescents", and keep citation 3,6,7.

5. In our reviewe, we discovered that abortion was typically more acceptable among the married adolescents compared to the single ones [18] and the decision makerswere most often the male partners

Change "in our reviewe" to "in our review".

\begin{abstract}
Author details
${ }^{1}$ Department of Health Policy and Management, School of Public Health, University of Zambia, Nationalist Road, P.O Box 50110, Lusaka, Zambia. ${ }^{2}$ Department of Health Promotion and Education, School of Public Health, University of Zambia, Lusaka, Zambia. ${ }^{3}$ Department of Epidemiology and Biostatistics, School of Public Health, University of Zambia, Lusaka, Zambia. ${ }^{4}$ Strategic Centre for Health Systems Metrics and Evaluations (SCHEME), Department of Epidemiology and Biostatistics, School of Public Health, University of Zambia, Lusaka, Zambia.
\end{abstract}

Received: 25 June 2019 Accepted: 25 June 2019

Published online: 02 July 2019

Reference

1. Munakampe, et al. Contraception and abortion knowledge, attitudes and practices among adolescents from low and middle-income countries: a systematic review. BMC Health Serv Res. 2018;18:909 https://doi.org/10. 1186/s12913-018-3722-5.

\footnotetext{
* Correspondence: margaratemuna@yahoo.com

${ }^{1}$ Department of Health Policy and Management, School of Public Health,

University of Zambia, Nationalist Road, P.O Box 50110, Lusaka, Zambia

${ }^{4}$ Strategic Centre for Health Systems Metrics and Evaluations (SCHEME),

Department of Epidemiology and Biostatistics, School of Public Health,

University of Zambia, Lusaka, Zambia

Full list of author information is available at the end of the article
}

(c) The Author(s). 2019 Open Access This article is distributed under the terms of the Creative Commons Attribution 4.0 International License (http://creativecommons.org/licenses/by/4.0/), which permits unrestricted use, distribution, and reproduction in any medium, provided you give appropriate credit to the original author(s) and the source, provide a link to the Creative Commons license, and indicate if changes were made. The Creative Commons Public Domain Dedication waiver (http://creativecommons.org/publicdomain/zero/1.0/) applies to the data made available in this article, unless otherwise stated. 